\title{
Research Methodology as SDLC Process in Image Processing
}

\author{
Monika Bhatnagar \\ Research Scholar, \\ Dr. K. N. Modi University, \\ Rajasthan, India
}

\author{
Prashant Kumar Singh \\ ISC Software Pvt Ltd, Bhopal, \\ India
}

\begin{abstract}
Research work in any area requires a predefined process to be fulfilled. To start with one first identifies the problem area. Then with the step by step analysis he or she comes out with some solution. If it is specifically looked into the research work done in the field of computer technology, it is seen that generally the motive is to build some software or hardware solutions to one's day to day problems. Anyone who is aware of the complete process of a computer system development knows that a system developed always go through System Development Life Cycle (SDLC) Process. Therefore, this paper shows how SDLC is an essential part of providing proof of whatever one is proposing as a software solution to one's problem especially in the case of image segmentation and classification of datamining.
\end{abstract}

\section{General Terms}

Software Engineering, Research Methodology

\section{Keywords}

SDLC, Research Methodology, Image Segmentation.

\section{INTRODUCTION}

With the evolution of Human Race the area of research came into origin. The research found its existence, be it in search of food or shelter in Stone Age or the need of having comfortable and good life in Modern Age. Research was always there when people were trying to find medicines of the prevailing incurable diseases, or they were trying to convert any chemical element into gold or trying to find existence of other living beings in the universe and many more with the infinite list. Now in terms of academics we can say that research can be defined as process in which one understands and defines or redefines a problem and tries to come to an answer or solution to that problem [1].

Moving on from research as overall area to research in the field of computer science it is seen that a lot of advancement has occurred in this area. Computer systems are no longer just some hardware devices processing some spreadsheets, text documents and doing mathematical calculations. The idea of advancements prevailing in the minds of people who want more and more sophisticated life and highly advanced gadgets lead to more and more elaborated research. The results of all the research has been products used in the day to day lives of people right from the household applications such as washing machines to products that are used in work places like internet, printers to products which have become the essential daily need such as a cellular phone.

It is stated here that all the products related to computers be it is hardware or an extremely advanced software concepts and products are all result of some kind of research. Now the idea of development of such products are certainly result of some research but the development of such product specially a software product is through some Software Development Life Cycle process. This paper shows how a research process in computer technology development follow the SDLC process taking example of implementation of Image Segmentation in image processing of Datamining.

\section{LITERATURE SURVEY}

In past many of the researchers have worked on various aspects of Software Development Life Cycle process. Generally, people compare various SDLC Models, try to identify which amongst the existing models can be best for a particular example or they propose some new models for a particular situation.

Shikha Maheshwari and Dinesh Ch. Jain in their work have compared various SDLC processes and have analyzed performance of various models based on some features.

Vishwas Massey and K.J.Satao in their paper [3] have also compared various SDLC Models for performance and have also proposed a new model for better performance.

But both the papers do not make a comparison between the research methodology and SDLC process.

\section{PROBLEM STATEMENT}

A research in the field of computer technology when comes up with an answer it makes use of Software Development Life Cycle Model for its implementation. This paper is going to show how this very statement works.

\section{PROPOSED SOLUTION}

Now since the problem statement is well understood the next step is to identify and understand the various terminologies. The work starts with explaining the overall process of System Development Life Cycle process followed by the overall process of Research Methodology.

\subsection{System Development Life Cycle}

The System Development Life Cycle process presents a sequence of activities for system designers and developers to follow for developing software efficiently and on prescribed time [3].

The System Development Life Cycle is the process of developing information systems making use of analysis, design, implementation, testing and maintenance. It is 
system used to build and maintain software systems [4].The systems development life cycle (SDLC) is a concept used in project management that describes the stages involved in an information system development project, starting from an initial feasibility study to maintenance of the completed application. The primary objectives of SDLC are to ensure the delivery of high quality systems using strong management controls to maximize productivity [6] .

The most well-known and widely used software development life cycles include: the waterfall, $\mathrm{V}$-shaped, evolutionary rapid

In Waterfall Model the development stages are distributed in five stages [5] as shown in Figure 1.

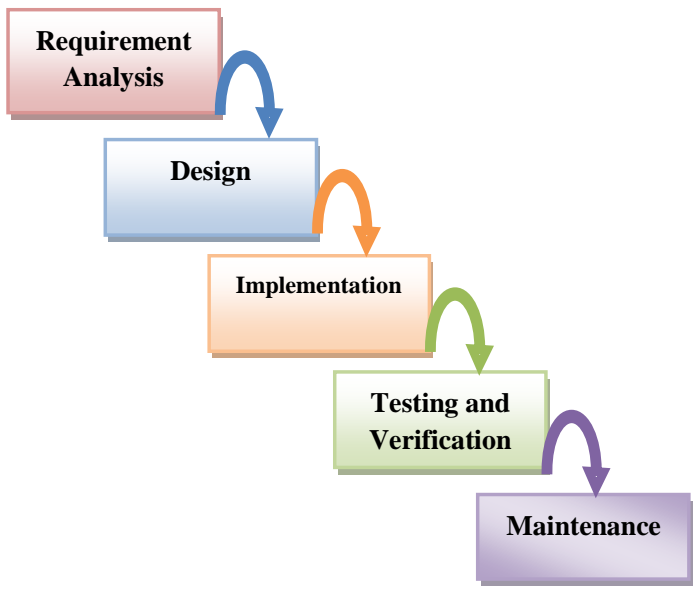

Figure 1. Water Fall Model

The relationship of each stage to the others can be roughly described as a waterfall, where the output from one stage serves as the initial input for the next stage. During each stage, additional information is gathered or developed, combined with the inputs, and used to produce the stage deliverables. Requirement analysis stage makes the analyst to understand the requirement of the product and its output. Based on the result of requirement analysis the Designer designs the requirement of the product on which the programmer or the implements writes the code using some specific tool. Once the code is ready it is tested in the testing phase which when is thoroughly correct id delivered to the customer who may asked to update or maintain it in the maintenance phase. This is the description of waterfall model.

\subsection{Research Methodology}

After explaining what the process of SDLC is now the process of Research Methodology is explained. To start with the term research is defined. Research is a process which may be defined as a careful investigation or inquiry especially through search for new facts in any area of knowledge.

Research methodology is a way to systematically solve the research problem [1]. It may be understood as a science of studying how research is done scientifically. In it the various steps that are generally adopted by a researcher in studying his research problem along with the logic behind them is studied. The process of research methodology can be seen in Figure 2 .

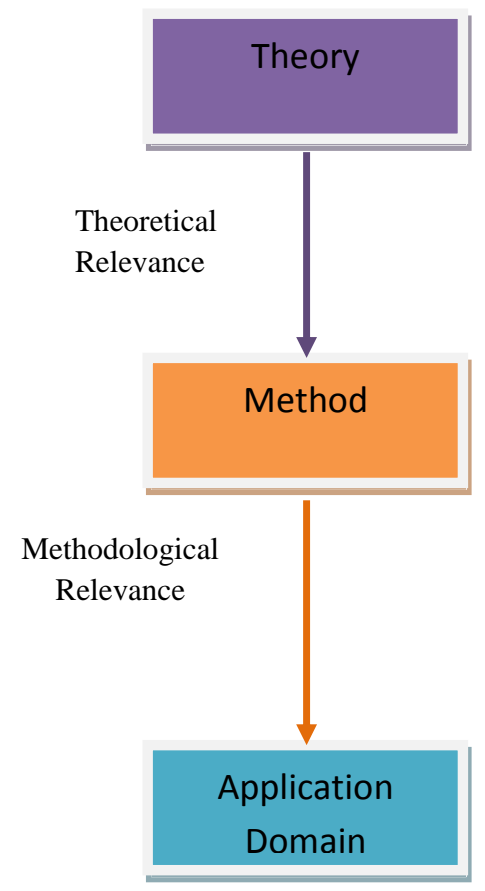

Figure 2. Process of Research Methodology

\section{EXPERIMENT AND RESULTS}

Now taking image segmentation of image processing from datamining as example it is shown that how an answer of a problem specified in this area will need SDLC process to get implemented. If it is not done the research will remain unguided which will lead to incomplete and inefficient research and will need longer time to prove its worth.

To start with the problem of the research is defined. The problem can be stated as in a given image as it is required to separate the desired image from the background of the image. Now stating the problem according to the research methodology it is required to understand and analyse the basic principle. When we are analysing the basic principle we are following the theory analysis of Research Methodology and following the requirement analysis phase of SDLC. So during this phase we understand the concept of datamining, image processing and image segmentation. Further when the theoretical relevance is tried to understand, the step by step procedure of image segmentation is well understood which then allows to create an algorithm which would be needed to implement the image segmentation. This part comes in the design phase of Waterfall model of SDLC process. In this case an algorithm can be stated as

(a) Choose a highest label L as cluster number

(b) A window size $\mathrm{N} * \mathrm{~N}$ is assigned.

(c) For each pixel in an image find the objects or shapes in an image to label them as $1,2,3 \ldots . . \mathrm{k}$.

(d) For the window Statistical Moment values are computed by calculating mean, variance, skewness using pixels of this window. 
(e) Considering the feature vectors consisting mean, variance, skewness, label classify pixel using K-Means classification technique.

(f) The result of this classification is the segmented image.

If any other diagram is required it is created. So we see that the requirement analysis phase and design phase of SDLC process can be summarized under the theory analysis part of the Research Methodology.

Next once the basic principles are known, an answer will be developed by implementing it which will certainly follow the implementation phase of SDLC process. This will also follow the method phase of Research Methodology. An implemented product can only be perfect if it goes through an extensive testing and verification phase successfully. So the next thing that comes under picture is again the testing and verification phase of SDLC process. If it is closely seen that the rigorous process that is followed in implementation and testing and verification phase is related to finding the methodological relevance which leads to the method phase of Research Methodology. The last stage of SDLC process is the maintenance phase which includes the delivering of the ready product to user and updating the product if required. So this is actually coming simultaneously to the application domain of the Research Methodology where the application of the solution to the problem presented in the research is produced.

Finally, the output of the implementation of the above stated algorithm making use of MATLAB 7 is presented. Figure 3 shows the input image. Figure 4 gives the result of edge detection of the input image. Finally Figure 5 shows the final result of segmentation.

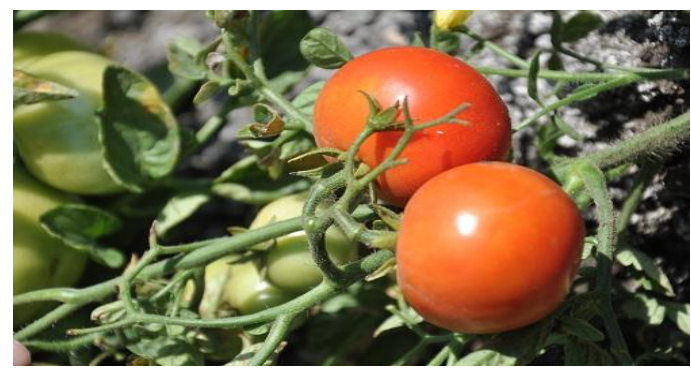

Figure 3. Tomato as input image

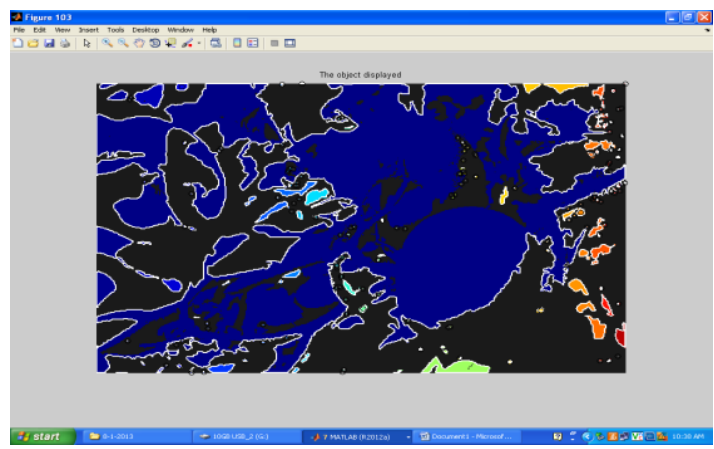

Figure 4. The result of edge detection of the input image

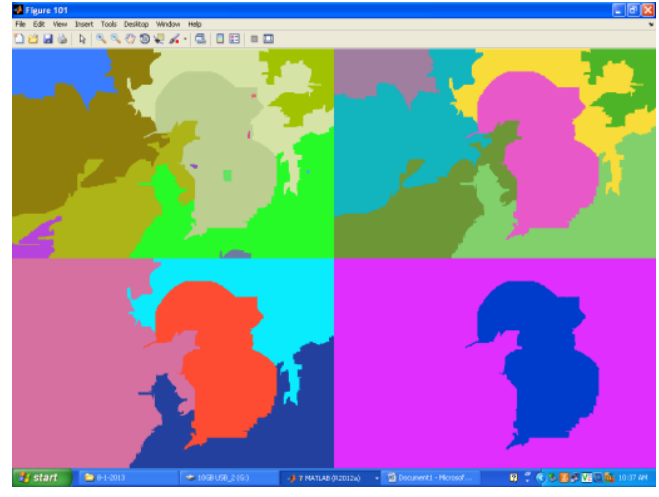

Figure 5. The result of segmentation in multiple colors.

Thus, we see that the SDLC process goes hand in hand with Research Methodology go hand in hand in the research work done in the area of computer technology and application to prove the worth of the result executed.

\section{CONCLUSION}

With all the work presented a complete comparative analysis was made between the two given processes viz. the Software Development Life Cycle Model and Research Methodology to show how they work hand in hand in the research in the area of computer technology. Thus, it is also seen that the research work when implemented if does not follow SDLC process will be inefficient and unguided. It will also take longer time than expected. Through all the process that was explained it be say that the research work done in the field of computer science when follows the step wise Research Methodology will make use of Software Development Life Cycle process to prove the authenticity of the solution especially in the field of image processing of datamining.

\section{REFERENCES}

[1] Ranjeet Kumar,"Research methodology A step by step guide for beginners ", pp 5-15, SAGE Publications Asia Pacific Ltd, ISBN 178-1-84920-300-5,3rd Edition.

[2] Shikha maheshwari, Dinesh Ch. Jain," A Comparative Analysis of Different types of Models in Software Development Life Cycle", published in International Journal of Advanced Research in Computer Science and Software Engineering(IJARCSSE), Volume 2, Issue 5, May 2012,pp 285-290, ISSN: 2277 128X.

[3] Vishwas Massey, K.J.Satao, “ Comparing Various SDLC Models And The New Proposed Model On The Basis Of Available Methodology”, published in International Journal of Advanced Research in Computer Science and Software Engineering(IJARCSSE), Volume 2, Issue 4, May 2012,pp 170-177, ISSN: 2277 128X.

[4] Robert T. Futrell, Donald F. Shafer,Linda I. Safer, "Quality Software Project Management", pp-25-50, Prentice Hall, ISBN-10: 0-13-091297-2

[5] Roger S Pressman," Software Engineering- A Practitioner's Approach “, pp-20-60, 2010, 7th edition, McGraw-Hill; ISBN-10: 9780073375977

[6] Mark McMurtrey, "A Case Study of the Application of the Systems Development Life Cycle (SDLC) in 21st Century Health Care: Something Old, Something New? ", Journal of Southern Association for Information Systems,Volume 1 Issue 1, Winter 2013, DOI http://dx.doi.org/10.3998/jsais.11880084.0001.103 